Editors' Note: Mortimer argues that important confounding variables may have biased the conclusion by Alladi et al. on the role of bilingualism in delaying the onset of dementia. Following Mortimer's comments, Alladi et al. conducted additional analysis of their data to support their conclusion. The attitude of "close enough" is not appropriate when determining brain death. Stadlan comments and supports Frank's call for action regarding this sensitive issue. —Chafic Karam, MD, and Robert C. Griggs, MD

\section{BILINGUALISM DELAYS AGE AT ONSET OF DEMENTIA, INDEPENDENT OF EDUCATION AND IMMIGRATION STATUS}

James A. Mortimer, Tampa, FL: From their study of 648 patients with dementia in a clinic in India, Alladi et al. concluded that bilingualism leads to a delay in onset age of dementia compared with monolingualism. ${ }^{1}$ The data are not sufficient to draw this conclusion. Age at onset studies conducted in a single disease group cannot indicate associations with risk factors because the age at onset depends on the age distributions of the groups from which the participants are selected in the source population.

If monolingual persons die at a younger age on average than their higher-educated bilingual counterparts, then the mean age of monolingual people in the source population will be lower than that of bilingual people. This difference will be reflected in the mean age at onset of any disease of later life, including dementing illnesses. To establish that the finding reflects cognitive reserve and is not an artifact of differing age distributions of monolingual and bilingual people in the source population, the age distribution of the source population by monolingualism/bilingualism needs to be determined.

In this study, monolingual patients had a lower education level and greater illiteracy, and they more frequently lived in a rural environment. These factors are known to be related to lower life expectancy. Adjusting for these factors in models restricted to cases cannot address the issue of differences in life expectancy in these groups in the source population.

Author Response: Suvarna Alladi, Hyderabad, India; Thomas H. Bak, Tom C. Russ, Edinburgh, UK; Mekala Shailaja, Vasanta Duggirala, Hyderabad, India: Dr. Mortimer raises the important issue of confounding variables, which are relevant to all observational studies. Our study controlled for these variables $^{1}$ to a higher degree than others. We succeeded in eliminating the immigration confound. We also examined illiterate monolingual and bilingual participants separately and found an even larger difference than among literate participants. Following Dr. Mortimer's comments, we conducted an additional analysis, examining rural participants $(\mathrm{n}=149)$ separately, and still found a difference between monolingual and bilingual participants (56.2 [10.9] vs 60.7 [9.6] years, $p<0.01$ ).

Our study was not a single disease study; our cohort comprised different types of dementia with different etiologies, symptomatologies, and, of importance, ages at presentation. If the differences in the age at onset were due to lower life expectancy among monolingual participants, we would expect to find the largest effect in those dementia types that present late. We found the opposite. The largest difference was found in frontotemporal dementia, which presents earlier than other dementias. ${ }^{2}$ In Alzheimer disease, presenting almost a decade later, the difference was smaller, and in dementia with Lewy bodies and mixed dementiathe highest age at presentation - the difference was the smallest. Future studies should further minimize potential confounding variables and this will better clarify these associations.

(C) 2014 American Academy of Neurology

1. Alladi S, Bak TH, Duggirala V, et al. Bilingualism delays age at onset of dementia, independent of education and immigration status. Neurology 2013;81:1938-1944.

2. Ratnavalli E, Brayne C, Dawson K, Hodges JR. The prevalence of frontotemporal dementia. Neurology 2002;58: $1615-1621$.

\section{PRACTICE VARIABILITY IN BRAIN DEATH DETERMINATION: A CALL TO ACTION}

Noam Y. Stadlan, Skokie, IL: Shappell et al. ${ }^{1}$ highlighted the problems concerning determinations of death. If documentation reflects reality, some patients were declared dead with neither an apnea test nor confirmatory testing. The attitude of "close enough" is not appropriate. The neurologic/neurosurgical community must ensure that determinations of death are properly done. Ancillary testing can ideally be 


\section{Neurology}

\section{Bilingualism delays age at onset of dementia, independent of education and immigration status}

James A. Mortimer, Suvarna Alladi, Thomas H. Bak, et al.

Neurology 2014;82;1936

DOI 10.1212/WNL.0000000000000400

This information is current as of May 26, 2014

\section{Updated Information \&} Services

References

Permissions \& Licensing

Reprints including high resolution figures, can be found at: http://n.neurology.org/content/82/21/1936.1.full

This article cites 2 articles, 2 of which you can access for free at: http://n.neurology.org/content/82/21/1936.1.full\#ref-list-1

Information about reproducing this article in parts (figures,tables) or in its entirety can be found online at:

http://www.neurology.org/about/about_the_journal\#permissions

Information about ordering reprints can be found online: http://n.neurology.org/subscribers/advertise

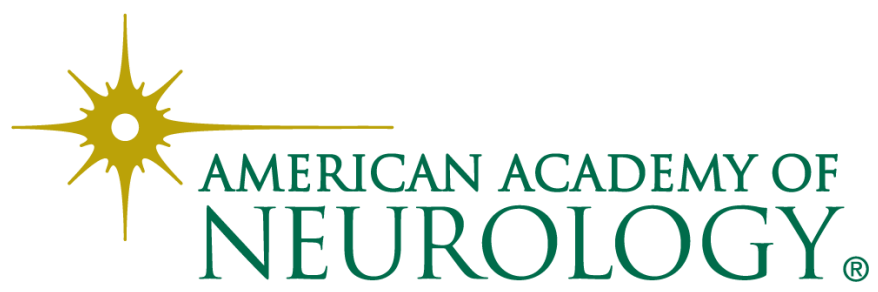

